\title{
Enrollment of Older Metastatic Breast Cancer Patients in First Line Clinical Trials: 9-Year Experience of the Large-Scale Real-Life Multicenter French ESME Cohort
}

\author{
Michael Bringuier ( $\nabla$ michael.bringuier@curie.fr ) \\ Institute Curie: Institut Curie https://orcid.org/0000-0002-7643-2956 \\ Matthieu Carton \\ Institut Curie \\ christelle Levy \\ Centre Francois Baclesse Centre de Lutte Contre le Cancer \\ Anne Patsouris \\ Institut de Cancérologie de l'Ouest: Institut de Cancerologie de l'Ouest \\ David Pasquier \\ Oscar Lambret Cancer Centre: Centre Oscar Lambret
}

\section{Marc Debled}

Institut Bergonié Département d' Oncologie Médicale: Institut Bergonie Departement d' Oncologie

Medicale

\section{Olivier Rigal}

Henri Becquerel Cancer Institute: Centre Henri Becquerel

\section{William Jacot}

Institut regional du Cancer de Montpellier

Anthony Goncalves

Paoli-Calmettes Institute: Institut Paoli-Calmettes

Isabelle Desmoulins

Centre Georges-François Leclerc: Centre Georges-Francois Leclerc

Thibault De La Motte Rouge

Eugene Marquis Cancer Institute: Centre Eugene Marquis

Thomas Bachelot

Leon Berard Hospital: Hopital Leon Berard

Jean-Marc Ferrero

CLCC Antoine-Lacassagne: Centre Antoine-Lacassagne

Jean-Christophe Eymard

Godinot Institute: Institut Godinot

Mony Ung 
IUCT Oncopole: Institut Universitaire du Cancer Toulouse Oncopole

\section{Marie-ange Mouret-reynier}

Jean Perrin Centre: Centre Jean Perrin

\section{Thierry Petit}

Paul Strauss Cancer Centre: Centre Paul Strauss

\section{Michaël Chevrot}

FNCLCC: UNICANCER

\section{Lionel Uwer}

Institut de Cancérologie de Lorraine: Institut de Cancerologie de Lorraine

\section{Coralie Courtinard}

FNCLCC: UNICANCER

\section{Jean-Sebastien Frenel}

Institut de Cancérologie de l'Ouest: Institut de Cancerologie de l'Ouest

\section{Alessandro Viansone}

Gustave Roussy Département de Médecine Oncologique: Gustave Roussy Departement de Medecine Oncologique

\section{Capucine Baldini}

Institute Gustave-Roussy: Gustave Roussy

\section{Research Article}

Keywords: geriatric oncology, breast cancer, clinical trial, epidemiology

Posted Date: June 22nd, 2021

DOI: https://doi.org/10.21203/rs.3.rs-627804/v1

License: (c) (i) This work is licensed under a Creative Commons Attribution 4.0 International License.

Read Full License

Version of Record: A version of this preprint was published at Breast Cancer Research and Treatment on January 5th, 2022. See the published version at https://doi.org/10.1007/s10549-021-06467-2. 


\section{Abstract}

Purpose: Older cancer patients are underrepresented in clinical trials. We aimed to understand barriers to clinical trial recruitment in women aged 70 years old (yo) or over with metastatic breast cancer (MBC).

Methods: We used the national Epidemio-Strategy and Medical Economics MBC Data Platform, a French multi-center real life database. We selected MBC women over 70yo, without central nervous system metastases, with at least one line of systemic treatment, between January $1^{\text {st }}, 2008$ and December $31^{\text {st }}$, 2016 , and had no other cancer in the 5 years before MBC. The primary objective was to evaluate the proportion of patients enrolled in clinical trials according to their age. Secondary objective was to identify variables associated with enrollment.

Results: 5552 women were aged $\geq 70$ (median 74yo; IQR72-77). 14611 were less than 70. Of the older ones, 239 (4\%) were enrolled in a clinical trial during first line of treatment, compared with 1529 (10.5\%) for younger ones. Multivariable analysis of variables predicting for enrollment during first line of treatment in older patients were younger age (OR 0.50 [95\% Cl; 0.33-0.76] for the 80-85yo class; OR 0.17 [95\%Cl; 0.06-0.39] for the 85yo and more class), good ECOG Performance Status (PS 0-1) (OR 0.15 [95\% Cl; 0.08-0.27] for the PS 2-4 class), HER2+ disease (OR 1.78 [95\% Cl; $1.27-2.48]$ ), type of treatment (chemotherapy/targeted therapy/immunotherapy OR 5.01 [95\% Cl; 3.13-8.18]), and period (OR 1.65 [95\%Cl; 1.22-2.26] for 2012-2016, compared to 2008-2011).

Conclusions: In this large database, few older MBC patients were enrolled in a trial compared with younger ones.

\section{Introduction}

Ageing is associated with an increased risk of cancer. In western countries, around $45 \%$ of breast cancer cases occur in women aged 65 years old or over and $20 \%$ in women over 75 years old [1]. Despite the recent advances in oncology treatments, older patients with metastatic breast cancer (MBC) still have poorer overall survival compared to their younger counterparts [2]. This might be due to later diagnosis, absence of screening, lack of knowledge of symptoms, neglect of clinical signs, physical and psychosocial barriers or occult disease presentation. Older patients display peculiarities such as changes in organ function associated with increasing age that can alter absorption, distribution, metabolism or excretion of drugs [3-4]. They also present more acute organ dysfunctions, due to more comorbidities, illustrating the concept of frailty [5]. Moreover, older patients with metastatic disease are underrepresented in clinical trials [6-11] with no progress in the last years [12]. They may present different efficacy and/or toxicity profiles compared with younger adults that can affect outcomes $[13,14]$. One recent study showed that the median age at inclusion in clinical trials of patients with breast cancer was7.76 years $[7.24,8.28]$ younger than the median age at diagnosis [6]. This underrepresentation led to therapeutic guidelines that may be inappropriate, or at least not personalized enough, for older patients. 
Successively, the FDA and the EMA issued guidance for including an adequate representation of older adults in cancer clinical trials to better define toxicity and efficacy in this population. They emphasize on the critical need to include adults over 75 years old especially in early phase trials to better extrapolate the results to the general population and have early pharmacokinetic and toxicity data [15-16]. A recent position paper [17] of the International Society of Geriatric Oncology (SIOG) classified as one of their 12 priority axes, a large participation of older patients in clinical research programs, as well as the development of research protocols dedicated to the older population. In this context, real life cohorts may bring valuable insight to identify potential barriers to recruitment of older patients with MBC in clinical trials. In this study, we aim to describe the enrollment of patients aged 70 years old or over with MBC in first line clinical trials in France in the past decade and to evaluate their outcomes in a multicenter real life cohort.

\section{Methods}

We used the national Epidemio-Strategy and Medical Economics (ESME) Metastatic Breast Cancer (MBC) Data Platform [18], a multi-center real life database using a retrospective data collection process in 18 French Cancer Centers. This database compiles data from Patient's Electronic medical records. Cases selected were adult patients with MBC whose first metastasis was treated between January $1^{\text {st }}, 2008$ and December $31^{\text {st }}, 2016$. In compliance with the authorization delivered by the French Data Protection agency to R\&D Unicancer (Registration ID 1704113 and authorization NDE-2013.-117, NCT03275311), only aggregated statistical reports were provided.

We selected women who were 70 years old or over at the time of MBC diagnosis, who received at least one line of systemic treatment and who had no other (non-breast) cancer in the 5 years before MBC, and lack of 'Central Nervous System' (CNS) metastases. The metastatic disease was defined as de novo when the metastases were diagnosed synchronously or $\leq 6$ months from diagnosis of the primary tumor; and as recurrent when the metastases were diagnosed $>6$ months from the diagnosis of the primary tumor. MBC treatment strategy could include chemotherapy (CT), targeted therapy (TT), and endocrine therapy (ET). Four subtypes were defined according to endocrine receptor (HR, estrogen and progesterone receptors) and HER2 status: HR+HER2-, HER2+ (regardless of ER status), HR-/HER2- (triple-negative, TN) and undetermined.

For the ESME MBC cohort, HER2 and HR statuses were derived from existing results about metastatic tissue sampling where available, or, if not available, from last sampling on early disease. Tumours were defined as HR positive if oestrogen receptor or progesterone receptor expression was $\geq 10 \%$ (immunohistochemistry). HER2 immunohistochemical (IHC) score 3+ or IHC score 2+ with a positive fluorescence in situ hybridisation (FISH) or chromogenic in situ hybridisation (CISH) classified the cancer as HER2 positive (HER2+). On the other hand, all cancers with an IHC score $0,1+$ or $2+$ with a negative $\mathrm{FISH} / \mathrm{CISH}$ test, as well as patients with a negative $\mathrm{FISH} / \mathrm{CISH}$ test without IHC information, were considered as HER2 negative (HER2-). Cancers with an IHC score 2+ without FISH/CISH test information were considered as HER2 undeterminate. Type of metastasis at MBC diagnosis was grouped as 'Not 
visceral' (including only bones and/or nodes metastases) and 'Visceral' (metastases other than bones and nodes). Number of metastatic sites at MBC diagnosis was described as $<3$ versus ${ }^{3} 3$. Year of MBC diagnosis was dichotomized according to the cut-off year 2012 (2008-2011 versus 2012-2016).

'Enrolment in a clinical trial' was registered in ESME MBC cohort, regardless of the type (systemic treatment, local treatment, supportive care for instance) and the phase of the trial (which consists of interventional studies, with authorization from health authorities and signing of informed consent, involving human volunteers, in intend to add to the medical knowledge). We focused on the enrollment in a clinical trial during the first line of treatment in metastatic setting.

The primary endpoint was the proportion of patients enrolled in clinical trials during the first line of treatment according to their age (threshold 70 years old). The secondary endpoints were variables associated with inclusion in a clinical trial in older patients (versus non included older patients), comparison of overall survival of older patients included in a trial versus non included, proportion of older patients enrolled between 2008-2011 and 2012-2016. A preliminary analysis was done with a comparison between patients selected for the primary analysis (aged 70 yo or more) and patients not selected (ie, aged $<70$ yo at $\mathrm{MBC}$ ).

\section{Statistical analysis}

Descriptive statistics were used to summarize patients' initial characteristics at diagnosis of metastatic disease. They were compared between groups using Chi-2's or Fisher's exact test for categorical data and Student T-test or non-parametric Wilcoxon's test for continuous data; a $\mathrm{p}$ value $<0.05$ was considered statistically significant. The reverse Kaplan-Meier method was used to estimate the median follow-up duration, beginning at the date of diagnosis of metastatic disease.

For the secondary endpoint (variables associated with inclusion in a clinical trial in older patients), in order to estimate the relative contribution of each variable, we used a multivariable logistic model. Variables included in the analysis were age at MBC diagnosis (continuous variable or in classes according to the age distribution in patients aged 70 and over), time from primary cancer to MBC diagnosis (de novo/recurrent), metastatic sites at diagnosis, phenotype (HER2+, HR+HER2- or TN), ECOG Performance status (0-1/2-4/not available), type of treatment (CT/TT/immunotherapy alone or with ET versus ET alone), years of MBC diagnosis (2008-2011 versus 2012-2016) and number in ESME database per center per year, also called "Center Cize" ( $<500 ; 500-800 ;>800$ new patients per year).

Overall survival (OS) was defined as time (in months) between MBC diagnosis and date of death (any cause) or censored to date of latest news. Survival curves for OS with associated log-rank tests were 
generated using the Kaplan Meier method.

A multivariable Cox model was performed to fit the model on the above-mentioned variables. Variables significant at a $10 \%$ level were included in a backward selection procedure to keep variables significant at a $5 \%$ level in the final multivariable model. Hazard Ratios (HR) are presented with $95 \%$ confidence interval (Cl). The effect of inclusion or non-inclusion in a clinical trial on survival was estimated with and without adjustment in a Cox model.

To take into account the impact of aging on the risk of death from other causes than cancer, specific survival was also estimated when information on the cause of death was available (overall, less than $50 \%$ of cases in ESME).

Similarly, the relative survival of patients included and patients not included in a clinical trial was estimated using the mortality tables by year, age, sex and year of birth in France (loaded at the web site of The Human Mortality Database).

A p-value of less than 0.05 was considered statistically significant.

All analyses were performed using the software R. (R Core Team (2017); the relative survival analysis was computed using Relsurv package of R.

\section{Results}

\section{Patients' characteristics}

On the 22463 patients of the ESME data base, we selected 5552 women aged $\geq 70$ yo and 14611 women aged $<70$ yo (Figure 1). The median age in the older group was 77 yo (Q1-Q3; 73-82). Time from primary breast cancer diagnosis to MBC was 52 months in the older population, compared to 31 months in patients under 70 years of age. Characteristics of patients, MBC and first line treatments are presented in Table 1. Most of the older patients (67\%) had an HR+ HER2- disease, $52 \%$ had visceral metastases and $82 \%$ had less than 3 metastatic sites at MBC diagnosis.

\section{Inclusion in clinical trials}

Among the older population, 239 (4\%) patients were enrolled in a clinical trial in the first line setting compared to $1529(10.5 \%)$ younger patients. When considering all lines of treatment, $7 \%$ of older women with MBC were enrolled in a clinical trial. Of note, the median follow-up was 46.7 (95\% $\mathrm{Cl} ; 45.1-49.3)$ months in older patients, compared to 54.2 months (95\%Cl; 53.3-55.4).

Median age at enrollment in first line in older patients was 74 yo [Q1-Q3; 72-77]. In first line, $0.3 \%$ of older patients were enrolled in phase I, $1.1 \%$ in phase II and $1.8 \%$ in phase III trials. The phase of the trial was unknown in up to $40 \%$. 
The proportion of older patients with $\mathrm{MBC}$ enrolled in clinical trials in the first line setting increased over time, with 172 older patients in the 2012-2016 period (5.6\%), compared to 67 older patients $(2.7 \%)$ in the 2008-2011 period. Inclusion of younger patients with MBC increased also over time, with 918 patients included in the 2012-2016 period (11.5\%), compared to 611 (9.2\%) in the 2008-2011 period.

If considering all-lines of treatment for enrollment in a clinical trial, the proportion of older patients enrolled also increased, with 244 older patients (8.0\%) in the 2012-2016 period compared to $151(6.1 \%)$ in the 2008-2011 period. In contrast, younger ones were less frequently enrolled with 1490 younger patients (18.7\%) in the 2012-2016 period compared to 1310 (19.8\%) in the 2008-2011 period. This is summarised in Figure 2.

\section{Variables associated with enrollment in clinical trials}

Multivariable analysis of variables associated with being enrolled in a first line clinical trial for the older patients aged 70yo and over is presented in Table 2. Bivariate analysis is presented in Supplementary Table 1. Among older women, variables associated with participation in a first line clinical trial in multivariable analysis were younger age (OR 0.50 [95\% Cl; 0.33-0.76] for the 80-85yo class; OR 0.17 [95\%Cl; 0.06-0.39] for the 85yo and more class), good ECOG Performance Status (PS 0-1) (OR 0.15 [95\% Cl; 0.08-0.27] for the PS 2-4 class; OR 0.19 [95\% Cl; 0.13-0.28] for unknown PS class), HER2+ disease (OR 1.78 [95\% Cl; $1.27-2.48]$ ), and type of treatment (chemotherapy/targeted therapy/immunotherapy OR 5.01 [95\% Cl; 3.13-8.18]; ET + chemotherapy/targeted therapy/immunotherapy OR 5.44 [95\% Cl; 3.598.50]). Being treated in the 2012-2016 period (compared to 2008-2011) was associated with an increased probability of enrollment in a first line clinical trial (OR 1.65 [95\% Cl; 1.22-2.26]. During the 2012-2016 period, $5.6 \%$ of older patients were enrolled compared to $2.7 \%$ during the $2008-2011$ period. Variables associated with enrollment of older patients in first line endocrine therapy trials were similar, with a 75 yo threshold (OR 0.61 [95\% Cl; 0.41-0.90]), instead of $80 y$ in the general population of older patients enrolled in a first line trial (Supplementary Table 2). Variables associated with enrollment of older patients in first line for chemotherapy/targeted therapy/immunotherapy trials were younger age (<80 yo) (OR 0.49 [95\%Cl; 0.30-0.77] for the 80-85yo class; OR 0.17 [95\% $\mathrm{Cl} ; 0.05-0.43$ ] for the $85 \mathrm{yo}$ and more class), ECOG PS0 (OR 0.69 [95\%Cl; 0.48-0.99] for PS1, OR 0.18 [95\%Cl; 0.09-0.32] for PS 2-4, OR 0.22 [95\%Cl; 0.15-0.33] for unknown PS; compared with PSO), HER2+ disease (OR 1.80 [95\% Cl; 1.30-2.49]) and the 2012-2016 period (OR 1.55 [95\% Cl; 1.13-2.15]). Triple negative (OR 0.58 [95\% Cl; $0.35-0.93]$ ) and unknown subtypes (OR 0.35 [95\% Cl; 0.11-0.86]) were associated with less enrollment in chemotherapy trials in older patients (Supplementary Table 3).

\section{Overall Survival}

Median overall survival (OS) was 34.8 months in the older population $(95 \% \mathrm{Cl} 33.6-36.0)$. Among older women, being enrolled in a trial in the first-line setting was associated with a better OS $(\mathrm{HR}=0.78 ; 95 \% \mathrm{Cl}$ 0.63-0.95) in the multivariable analysis (Table 3 and Figure 3 ). Similar results were observed for relative survival (Figure 4). 


\section{Discussion}

In this real-life French multicenter cohort, we found that only $4.3 \%$ of older women aged $70 y o$ or more with MBC were included in a clinical trial in the first-line setting, compared to $10.5 \%$ for their younger counterparts. When considering all lines of treatment, $7.1 \%$ of older women with MBC were enrolled in a clinical trial.

Several studies [6-12] are consistent with our results showing that older patients were less frequently enrolled in clinical trials, but none of them was specifically dedicated to metastatic breast cancer patients. Moreover, some of these studies were focused on the age of the patients included in clinical trials compared to the median age of disease incidence [6-8, 12]. Other studies were centered on patients treated for gastro intestinal cancer [9], included a small number of patients [10], or used a threshold of 65 years old [11].

In a prospective multicentric French cohort study (Sujets AGés dans les Essais Cliniques - SAGE), evaluating enrollment of patients with colorectal cancer, the inclusion rate with a threshold of 70 yo or more was $9.5 \%$ [9]. In the SEER data-base including all tumor types [12], $20 \%$ of older patients aged 70 yo or more were enrolled in a clinical trial, far more than our population. As stated by the authors, this high level of enrollment was related to numerous adjuvant endocrine therapy programs, which can lead to more enrollment consistent with the better general condition of this population. The inclusion rate excluding those studies was $12 \%$. Similarly, in Lackman's study [11], enrollment rate was up to $14 \%$, probably due to the high of proportion of non metastatic patients (66\%), and to a lower age threshold of 65 yo.

This low rate of enrollment in MBC was also observed in the OMEGA study, with several barriers to enrollment, such as patients' refusal of chemotherapy or randomization, comorbidities and oncologist's preferences [19]. Other barriers to enrollment have also been described [11-12,20] such as availability of trials, older age, ECOG PS, but also the representations of patients and practitioners on the potential benefits and risks expected from the protocol on an individual basis.

In our study, variables associated with participation in a clinical trial in the first-line setting in older patients were younger age (< 80 yo), good ECOG PS (0-1), HER2+ disease, and investigational treatment (chemotherapy/targeted therapy/immunotherapy trials). This is consistent with the SAGE and Lackman's studies $[9,11]$. In the SAGE study, older age ( $>80$ years old) was significantly associated with noninvitation to participate in a clinical trial $(\mathrm{HR}=0.14 ; 95 \% \mathrm{Cl} 0.02-0.60)$.

The type of disease (HR+ etc.), and the trials available at that time, with their inclusion and exclusion criteria, are important confounding factors, which should lead to some caution in the analysis of these results. The fact that patients were less included in endocrine therapy alone trials is probably due to the few trials enrolling at that time. Conversely, patients harboring HER2+ disease were more often enrolled in clinical trials due to a larger range of clinical trials in this indication. Poor ECOG PS (>1) is an usual exclusion criteria in trials, explaining our results with an OR of 0.15 in this patients' population. 
We also found a better overall survival in older MBC patients included during the first-line setting, and a better relative survival, even after adjustments for confounding factors in a multivariable analysis. This can be interpreted in two ways: one is that patients included in clinical trials have a better natural prognosis and are selected for trials because of their better general condition. The other could be that having access to innovative treatments may increase life expectancy among these patients. Our data do not allow to identify the respective weight of these two potential complementary factors linked to a longer observed survival, because of the retrospective setting, and lack of certain data (unavailable ECOG PS values in almost $50 \%$ and unavailable comorbidities, geriatric assessments and causes of death). Of note, a better overall survival when included in a clinical trial was also observed in the Korean MBC Database in a general MBC population [21].

Unfortunately, as mentioned, no geriatric data was available to better characterize older patients, such as cognitive status, depression, or functional autonomy, which could highly change the probability of enrollment in a clinical trial. The number of referrals, patient's eligibility and finally numbers of patients enrolled were not available in this database preventing from any conclusions regarding patient's selection. Finally, due to its retrospective nature, data regarding study type (chemotherapy, supportive care or radiotherapy for example) or study phase, was lacking in up to $40 \%$ in chemotherapy studies. The QUALISAGE study (NCT03230305), closed to enrollment, will probably help to answer these questions.

Finally, in our study, more patients were included during the 2012-2016 period compared to the 2007-2011 period. This improvement was also observed in younger patients in the first line setting. However, the inclusion rate of older patients increased over time when all treatment lines were taken into account, unlike younger patients. This encouraging result combined with the smaller increase of inclusion rate among younger people in the first line setting, suggest an improved awareness. Efforts are still needed for a better representation and reliable guidelines [22-23].

\section{Conclusion}

In this large real-life database, fewer older MBC patients were enrolled in a trial compared to younger ones. In older patients, variables associated with such participation to clinical research were younger age (< 80 yo), good ECOG Performance Status (0-1), HER2+ disease, and investigational treatment consisting of chemotherapy/targeted therapy/immunotherapy. Older patients were more enrolled in clinical trials between 2012 and 2016 compared to the 2008-2011 period (5.6\% versus 2.7\%). Most of these factors raise questions on drug availability and perceived potential benefits by investigators and medical teams. Accrual of older patients with cancer in MBC and other disease types should be more encouraged.

\section{Declarations}


Funding: This work was supported by R\&D UNICANCER. The study was not funded in whole or in part by any research grant or funding body

Conflicts of interest/Competing interests: All authors declare no potential conflict of interest relevant to the content of the manuscript.

Availability of data and material: The datasets analyzed during the current study are available in the Epidemio-Strategy and Medical Economics (ESME) Metastatic Breast Cancer (MBC) Data Platform. The database of the ESME program or the database of the MBC cohorts are currently not accessible. For any specific demand, please contact the corresponding author. Each demand will be examined on a case-by-case basis by the scientific committee

Code availability: All analyses were performed using the software R. (R Core Team (2017).

Authors' contributions: $M B$ conceived the study. $M B, M C, A V$ and $C B$ contributed to the design of the study. $\mathrm{MC}$ contributed to the acquisition and analysis of the data. $\mathrm{MB}, \mathrm{MC}, \mathrm{AV}$ and $\mathrm{CB}$ drafted the manuscript. All authors contributed to the interpretation of data, critically revised the manuscript, and gave final approval.

Ethics approval: The ESME MBC database received approval from the French data protection authority (Commission Nationale de l'Informatique et des Libertés, authorisation no. 1704113).

\section{Acknowledgments}

The authors thank the 18 French Comprehensive Cancer Centers for providing the data and each ESME contact for coordinating the project at the local level. We thank the ESME Scientific Committee members and the GERICO-DIALOG intergroup for their ongoing support.

\section{References}

1. National Cancer Institute. Surveillance, Epidemiology, and End result Program. https://seer.cancer.gov/statfacts/html/breast.html. Accessed 10 September 2020

2. Contemporary outcomes of metastatic breast cancer among 22,000 women from the multicentre ESME cohort 2008-2016. Deluche E, Antoine A, Bachelot T \& al. Eur J Cancer. 2020 Apr;129:60-70. doi:10.1016/j.ejca.2020.01.016. Epub 2020 Mar 2. PMID: 32135312

3. Pharmacology of cancer chemotherapy in the older person. Backer SD, Grochow LB. Clin Geriatr Med. 1997 Feb; 13(1):169-183

4. Altered pharmacokinetics in the elderly (1990 May) Yuen GJ. Clin Geriatr Med 6(2):257-267. PMID: 2184922

5. Frailty in elderly people. Clegg A, Young J, Iliffe \&al. Lancet (2013) Mar 2;381(9868):752 - 62. doi: 10.1016/S0140-6736(12)62167-9. Epub 2013 Feb 8. Erratum in: Lancet. 2013 Oct 19;382(9901):1328. PMID: 23395245; PMCID: PMC4098658 
6. Factors Associated With Age Disparities Among Cancer Clinical Trial Participants. Ludmir EB, Mainwaring W, Lin TA \& al. JAMA Oncol. 2019 Jun 3. doi:10.1001/jamaoncol.2019.2055. [Epub ahead of print]

7. Representation of older patients in cancer treatment trials. Trimble EL, Carter CL, Cain D \& al. Cancer 1994; 74(7 Suppl): 2208-2214

8. Inclusion of elderly patients in oncology clinical trials. Le Saux O, Falandry C, Gan HK \& al Annals of Oncology 2016; 27:1799-1804

9. Inclusion of Older Patients with Cancer in Clinical Trials: The SAGE Prospective Multicenter Cohort Survey. Canouï-Poitrine F, Lièvre A, Dayde F \& al. Oncologist (2019) Jul 19. pii: theoncologist.20190166. doi: 10.1634/theoncologist.2019-0166. [Epub ahead of print]

10. Underrepresentation of vulnerable older patients with cancer in phase II and III oncology registration trials: A case-control study. Tack L, Lefebvre T, Lycke M \& al J Geriatr Oncol 2020; 11; 320-326

11. Physician-reported reasons for non-enrollment of older adults in cancer clinical trials. Lackman $M$, Vickers MM, Hsu T. J Geriatr Oncol 2020; 11; 31-36

12. Enrollment of elderly patients in clinical trials for cancer drug registration: a 7-year experience by the US Food and Drug Administration. Talarico L, Chen G, Pazdur R J Clin Oncol 2004; 22(22): 46264631

13. Comparison of toxicity experienced by older versus younger patients enrolled in breast cancer clinical trials. Mariano C, Francl M, Pope J \& al. Clin Breast Cancer. 2015 Feb;15(1):73-79. doi: 10.1016/j.clbc.2014.09.002. Epub 2014 Sep 28. PMID: 25445420

14. Anticancer drugs are (oct 2020) not well tolerated in all older patients with cancer. Wildiers $\mathrm{H}$, Glas NA. Lancet Healthy Longev 1(1):e43-e47 1 (

15. Inclusion of Older Patients in Cancer Clinical Trials. Guidance For Industry. FDA. March 2020. https://www.fda.gov/media/135804/download. Accessed 09 February 2021

16. EMA geriatric medicines strategy. EMA (February 2011) https://www.ema.europa.eu/en/documents/other/geriatric-medicines-strategy_en.pdf. Accessed 09 February 2021

17. Priorities for the global advancement of care for older adults with cancer: an update of the International Society of Geriatric Oncology Priorities Initiative. Extermann M, Brain E, Canin B. \& al. Lancet Oncol 2021; 22: e29-e36

18. The ongoing French metastatic breast cancer (MBC) cohort: the example-based methodology of the Epidemiological Strategy and Medical Economics (ESME). Pérol D, Robain M, Arveux P, \& al. BMJ Open 2019;9(2):e023568

19. Slow accrual of elderly patients with metastatic breast cancer in the Dutch multicentre OMEGA study. Hamaker ME, Seynaeve C, Nortier JW \& al. Breast. 2013 Aug;22(4):556-559. doi:10.1016/j.breast.2012.12.010. Epub 2013 Jan 8. PMID: 23305962

20. Barriers to clinical trial enrollment of older adults with cancer: A qualitative study of the perceptions of community and academic oncologists. Sedrak MS, Mohile SG, Sun V \& al J Geriatr Oncol. 
2020;11(2):327-334

21. The Impacts of Inclusion in Clinical Trials on Outcomes among Patients with Metastatic Breast Cancer (MBC). Lee JY, Lim SH, Lee MY \& al. PLoS One (2016) Feb 22;11(2):e0149432. doi: 10.1371/journal.pone.0149432. PMID: 26901062; PMCID: PMC4763476

22. Designing therapeutic clinical trials for older and frail adults with cancer: U13 conference recommendations. Hurria A, Dale W, Mooney M \& al. J Clin Oncol (2014) Aug 20;32(24):2587-94. doi: 10.1200/JC0.2013.55.0418. PMID: 25071116; PMCID: PMC4129504

23. Older adult participation in cancer clinical trials: A systematic review of barriers and interventions. Sedrak MS, Freedman RA, Cohen HJ \& al. CA Cancer J Clin. 2021 Jan;71(1):78-92. doi: 10.3322/caac.21638. Epub 2020 Oct 1. PMID: 33002206; PMCID: PMC7854940

\section{Tables}

Table 1: Characteristics of women, metastatic breast cancers (MBC), first line treatments according to age category. 
Age at MBC diagnosis $\mathrm{n}(\%)$

\begin{tabular}{|c|c|c|c|c|c|}
\hline \multirow[t]{2}{*}{ Variable } & \multirow[t]{2}{*}{ Classe } & \multirow{2}{*}{$\begin{array}{l}<70 \text { years } \\
\mathrm{N}=14611\end{array}$} & \multirow{2}{*}{$\begin{array}{l}370 \text { years } \\
N=5552\end{array}$} & \multirow[t]{2}{*}{ Total } & \multirow[t]{2}{*}{ Chi2 p } \\
\hline & & & & & \\
\hline \multirow[t]{2}{*}{ Year of MBC diagnosis } & $2008-2011$ & $\begin{array}{l}6623 \\
(45.3 \%)\end{array}$ & 2492 (44.9\%) & 9115 (45.2\%) & \multirow[t]{2}{*}{0.57} \\
\hline & $2012-2016$ & $\begin{array}{l}7988 \\
(54.7 \%)\end{array}$ & $3060(55.1 \%)$ & $11048(54.8 \%)$ & \\
\hline \multirow[t]{3}{*}{ MBC status } & Recurrent & $\begin{array}{l}9913 \\
(68.0 \%)\end{array}$ & $3933(71.1 \%)$ & $13846(68.8 \%)$ & \multirow[t]{3}{*}{$<0.001$} \\
\hline & De novo & $\begin{array}{l}4664 \\
(32.0 \%)\end{array}$ & 1601 (28.9\%) & $6265(31.2 \%)$ & \\
\hline & NA & 34 & 18 & 52 & \\
\hline \multirow[t]{2}{*}{$\begin{array}{l}\text { Type of metastases (at } \\
\text { diagnosis) }\end{array}$} & $\begin{array}{l}\text { Not } \\
\text { visceral }\end{array}$ & $\begin{array}{l}6590 \\
(45.1 \%)\end{array}$ & 2662 (47.9\%) & 9252 (45.9\%) & \multirow[t]{2}{*}{$<0.001$} \\
\hline & Visceral & $\begin{array}{l}8021 \\
(54.9 \%)\end{array}$ & $2890(52.1)$ & $\begin{array}{l}10 \\
911(54.1 \%)\end{array}$ & \\
\hline \multirow[t]{2}{*}{$\begin{array}{l}\text { No. of organ sites (at } \\
\text { diagnosis) }\end{array}$} & $<3$ & $\begin{array}{l}11739 \\
(80.3 \%)\end{array}$ & 4575 (82.4\%) & 16314 (80.9\%) & \multirow[t]{2}{*}{0.001} \\
\hline & 33 & $\begin{array}{l}2872 \\
(19.7 \%)\end{array}$ & 977 (17.6\%) & 3849 (19.1\%) & \\
\hline \multirow[t]{4}{*}{ Subtype } & HR+ HER2- & $\begin{array}{l}9162 \\
(62.7 \%)\end{array}$ & 3699 (66.6\%) & $\begin{array}{l}12 \\
861(63.8 \%)\end{array}$ & \multirow[t]{4}{*}{$<0.001$} \\
\hline & HER2+ & $\begin{array}{l}2780 \\
(19.0 \%)\end{array}$ & $727(13.1 \%)$ & 3507 (17.4\%) & \\
\hline & $\mathrm{TN}$ & $\begin{array}{l}1977 \\
(13.5 \%)\end{array}$ & $486(8.8 \%)$ & $2463(12.2 \%)$ & \\
\hline & NA & $\begin{array}{l}692 \\
(4.7 \%)\end{array}$ & $640(11.5 \%)$ & 1332 (6.6\%) & \\
\hline \multirow[t]{4}{*}{ ECOG Performance status } & 0 & $\begin{array}{l}3816 \\
(26.1 \%)\end{array}$ & $573(10.3 \%)$ & $4389(21.8 \%)$ & \multirow[t]{4}{*}{$<0.001$} \\
\hline & 1 & $\begin{array}{l}2748 \\
(18.8 \%)\end{array}$ & 947 (17.1\%) & 3695 (18.3\%) & \\
\hline & $2-4$ & $\begin{array}{l}1070 \\
(7.3 \%)\end{array}$ & $856(15.4 \%)$ & 1926 (9.6\%) & \\
\hline & NA & $\begin{array}{l}6977 \\
(47.8 \%)\end{array}$ & $3176(57.2 \%)$ & $\begin{array}{l}10 \\
153(50.4 \%)\end{array}$ & \\
\hline \multirow[t]{2}{*}{$\begin{array}{l}\text { Type of } 1^{\text {st }} \text { line systemic } \\
\text { treatment (HR+ HER2-) }\end{array}$} & ET alone & $\begin{array}{l}3115 \\
(34.0 \%)\end{array}$ & $2300(62.2 \%)$ & $5415(42.1 \%)$ & \multirow[t]{2}{*}{$<0.001$} \\
\hline & & Page $13 / 22$ & & & \\
\hline
\end{tabular}


Age at MBC diagnosis n (\%)

\begin{tabular}{|c|c|c|c|c|c|}
\hline \multirow[t]{4}{*}{ Variable } & \multirow[t]{2}{*}{ Classe } & \multirow{2}{*}{$\begin{array}{l}<70 \text { years } \\
\mathrm{N}=14611\end{array}$} & \multirow{2}{*}{$\begin{array}{l}{ }^{3} 70 \text { years } \\
N=5552\end{array}$} & \multirow[t]{2}{*}{ Total } & \multirow[t]{2}{*}{ Chi2 p } \\
\hline & & & & & \\
\hline & $\begin{array}{l}\mathrm{CT} / \mathrm{TT} / \mathrm{IT} \\
\text { alone }\end{array}$ & $\begin{array}{l}1900 \\
(20.7 \%)\end{array}$ & 442 (11.9\%) & 2342 (18.2\%) & \\
\hline & $\begin{array}{l}\mathrm{ET}+ \\
\mathrm{CT} / \mathrm{TT} / \mathrm{IT}\end{array}$ & $\begin{array}{l}4147 \\
(45.3 \%)\end{array}$ & 957 (25.9\%) & 5104 (39.7\%) & \\
\hline \multirow[t]{3}{*}{$\begin{array}{l}\text { Type of } 1^{\text {st }} \text { line systemic } \\
\text { treatment (HER2+) }\end{array}$} & ET alone & $\begin{array}{l}176 \\
(6.3 \%)\end{array}$ & 135 (18.6\%) & 311 (8.9\%) & \multirow[t]{3}{*}{$<0.001$} \\
\hline & $\begin{array}{l}\mathrm{CT} / \mathrm{TT} / \mathrm{IT} \\
\text { alone }\end{array}$ & $\begin{array}{l}1573 \\
(56.6 \%)\end{array}$ & 344 (47.3\%) & 1917 (54.7\%) & \\
\hline & $\begin{array}{l}\mathrm{ET}+ \\
\mathrm{CT} / \mathrm{TT} / \mathrm{IT}\end{array}$ & $\begin{array}{l}1031 \\
(37.1 \%)\end{array}$ & 248 (34.1\%) & 1279 (36.5\%) & \\
\hline \multirow{3}{*}{$\begin{array}{l}\text { Type of } 1^{\text {st }} \text { line systemic } \\
\text { treatment (TN) }\end{array}$} & ET alone & 27 (1.4\%) & 15 (3.1\%) & $42(1.7 \%)$ & \multirow[t]{3}{*}{0.022} \\
\hline & $\begin{array}{l}\text { CT/TT/IT } \\
\text { alone }\end{array}$ & $\begin{array}{l}1909 \\
(96.6 \%)\end{array}$ & 458 (94.2\%) & 2367 (96.1\%) & \\
\hline & $\begin{array}{l}\mathrm{ET}+ \\
\mathrm{CT} / \mathrm{TT} / \mathrm{IT}\end{array}$ & $41(2.1 \%)$ & $13(2.7 \%)$ & $54(2.2 \%)$ & \\
\hline \multirow[t]{3}{*}{$\begin{array}{l}\text { Type of } 1^{\text {st }} \text { line systemic } \\
\text { treatment (unknow phenotype) }\end{array}$} & ET alone & $\begin{array}{l}284 \\
(41 \%)\end{array}$ & 467 (73\%) & 751 (56.4\%) & \multirow[t]{3}{*}{$<0.001$} \\
\hline & $\begin{array}{l}\mathrm{CT} / \mathrm{TT} / \mathrm{IT} \\
\text { alone }\end{array}$ & $\begin{array}{l}204 \\
(29.5 \%)\end{array}$ & 76 (11.9\%) & $280(21.0 \%)$ & \\
\hline & $\begin{array}{l}\mathrm{ET}+ \\
\mathrm{CT} / \mathrm{TT} / \mathrm{IT}\end{array}$ & $\begin{array}{l}204 \\
(29.5 \%)\end{array}$ & 97 (15.2\%) & 301 (22.6\%) & \\
\hline \multirow[t]{2}{*}{$\begin{array}{l}\text { Enrollment in clinical trial } \\
\text { during } 1^{\text {st }} \text { line treatment }\end{array}$} & No & $\begin{array}{l}13082 \\
(89.5 \%)\end{array}$ & $5313(95.7 \%)$ & $\begin{array}{l}18 \\
395(91.2 \%)\end{array}$ & \multirow[t]{2}{*}{$<0.001$} \\
\hline & Yes & $\begin{array}{l}1529 \\
(10.5 \%)\end{array}$ & 239 (4.3\%) & 1768 (8.8\%) & \\
\hline \multirow[t]{3}{*}{ Center size } & $<500$ & $\begin{array}{l}713 \\
(4.9 \%)\end{array}$ & 312 (5.6\%) & 1025 (5.1\%) & \multirow[t]{3}{*}{0.075} \\
\hline & $500-800$ & $\begin{array}{l}10090 \\
(69.1 \%)\end{array}$ & 3834 (69.1\%) & $\begin{array}{l}13 \\
924 \text { (69.1\%) }\end{array}$ & \\
\hline & $>800$ & $\begin{array}{l}3808 \\
(26.1 \%)\end{array}$ & 1406 (25.3\%) & 5214 (25.9\%) & \\
\hline
\end{tabular}


TN: Triple Negative (HR- HER2-). ET: Endocrine Therapy. CT/TT/IT: chemotherapy/Targeted Therapy/Immunotherapy. "Center size" represent the number of enrollment in ESME database per center per year

Table 2: Multivariate odds ratios associated with being included in a trial in first-line of treatment in patients aged 70yo or more with Metastatic Breast Cancer (MBC).

*percentage of patients included in a first-line therapeutic trial 
n $\%$ incl.* OR $95 \% \mathrm{Cl}$ p value

\section{Age at MBC diagnosis - class}

[70-75[

[75-80[

[80-85[

[85 and more[

\section{Year of MBC diagnosis}

2008-2011

2012-2016

Type of metastases (at diagnosis)

Not visceral

Visceral

No. of organ sites (at diagnosis)

$<3$

${ }^{3} 3$

Subtype

HR+ HER2-

HER2+

TN

Unknown

ECOG Performance status

0

1

2-4

NA

Type of systemic treatment in $1^{\text {st }}$ line

ET alone

CT/TT/IT alone

$\mathrm{ET}+\mathrm{CT} / \mathrm{TT} / \mathrm{IT}$ $\begin{array}{llll}1898 & 6.95 & 1 & \text { ref }\end{array}$

$\begin{array}{lllll}1696 & 4.19 & 0.74 & {[0.54 ; 1.01]} & 0.058\end{array}$

$\left.\begin{array}{lllll}1258 & 2.46 & 0.50 & {[0.33 ; 0.76}\end{array}\right] 0.001$

$\begin{array}{ll}700 & 0.71\end{array}$

0.17

$[0.06 ; 0.39]<0.001$

$\left.\begin{array}{lllll}3060 & 5.62 & 1.65 & {[1.22 ; 2.26}\end{array}\right] \quad 0.001$

$\begin{array}{llll}2662 & 3.38 & 1 & \text { ref }\end{array}$

$\begin{array}{lllll}2890 & 5.16 & 1.10 & {[0.81 ; 1.50]} & 0.5\end{array}$

\begin{tabular}{lllll}
4575 & 4 & 1 & ref & \\
\hline 977 & 5.73 & 1.01 & {$[0.70 ; 1.44]$} & 0.94
\end{tabular}

$\begin{array}{llll}3699 & 3.68 & 1 & \text { ref }\end{array}$

$\begin{array}{lllll}727 & 10.18 & 1.78 & {[1.27 ; 2.48}\end{array}<0.001$

$\begin{array}{lllll}486 & 4.53 & 0.68 & {[0.39 ; 1.14]} & 0.15\end{array}$

$\left.\begin{array}{lllll}640 & 1.09 & 0.47 & {[0.19 ; 0.96}\end{array}\right] \quad 0.059$


Center size

\begin{tabular}{llllll}
\hline$<500$ & 312 & 2.88 & 1 & ref & \\
\hline $500-800$ & 3834 & 4.93 & 1.47 & {$[0.76 ; 3.20]$} & 0.29 \\
\hline$>800$ & 1406 & 2.92 & 0.68 & {$[0.33 ; 1.54]$} & 0.32
\end{tabular}

OR: Odds Ratio. TN: Triple Negative (HR- HER2-). ET: Endocrine Therapy. CT/TT/IT:

chemotherapy/Targeted Therapy/Immunotherapy. "Center size" represent the number of enrollment in ESME database per center per year

Table 3: Multivariable Analysis of factors associated with Overall Survival in Older Patients with Metastatic Breast Cancer (MBC). 


\begin{tabular}{|c|c|c|c|c|c|}
\hline Variables & Categories & $\mathbf{N}$ & HR & $95 \% \mathrm{Cl}$ & $P$ value \\
\hline \multirow[t]{2}{*}{ Enrollment in clinical trial - L1 } & No & 5313 & 1 & & \multirow[t]{2}{*}{$<0.001$} \\
\hline & Yes & 239 & 0.78 & {$[0.63 ; 0.95]$} & \\
\hline \multirow[t]{4}{*}{ Age at $\mathrm{MBC}$ diagnosis } & [70-75[ & 1898 & 1 & & \multirow[t]{4}{*}{$<0.001$} \\
\hline & {$[75-80[$} & 1696 & 1.16 & {$[1.06 ; 1.26]$} & \\
\hline & [80-85[ & 1258 & 1.35 & {$[1.23 ; 1.49]$} & \\
\hline & [85 and more[ & 700 & 1.87 & {$[1.67 ; 2.11]$} & \\
\hline \multirow[t]{2}{*}{ Year of MBC diagnosis } & $2008-2011$ & 2492 & 1 & & \multirow[t]{2}{*}{0.8} \\
\hline & $2012-2016$ & 3060 & 1.01 & {$[0.94 ; 1.09]$} & \\
\hline \multirow[t]{2}{*}{ Type of metastasis (at diagnosis) } & Not visceral & 2662 & 1 & & \multirow[t]{2}{*}{$<0.001$} \\
\hline & Visceral & 2890 & 1.34 & {$[1.24 ; 1.45]$} & \\
\hline \multirow[t]{2}{*}{ No. of organ sites (at diagnosis) } & $<3$ & 4575 & 1 & & \multirow[t]{2}{*}{$<0.001$} \\
\hline & $>=3$ & 977 & 1.39 & {$[1.26 ; 1.53]$} & \\
\hline \multirow[t]{4}{*}{ Subtype } & HR+HER2- & 3699 & 1 & & \multirow[t]{4}{*}{$<0.001$} \\
\hline & HER2+ & 727 & 0.74 & {$[0.65 ; 0.83]$} & \\
\hline & TN & 486 & 1.32 & {$[1.15 ; 1.51]$} & \\
\hline & Unknown & 640 & 0.96 & {$[0.86 ; 1.07]$} & \\
\hline \multirow[t]{4}{*}{ ECOG Performance status } & 0 & 573 & 1 & & \multirow[t]{4}{*}{$<0.001$} \\
\hline & 1 & 947 & 1.18 & {$[1.01 ; 1.37]$} & \\
\hline & $2-4$ & 856 & 2.57 & {$[2.21 ; 3.01]$} & \\
\hline & NA & 3176 & 1.79 & {$[1.56 ; 2.05]$} & \\
\hline \multirow[t]{3}{*}{ Type of systemic treatment in $1^{\text {st }}$ line } & ET alone & 2917 & 1 & & \multirow[t]{3}{*}{$<0.001$} \\
\hline & $\mathrm{CT} / \mathrm{TT} / \mathrm{IT}$ alone & 1320 & 2.12 & {$[1.91 ; 2.36]$} & \\
\hline & $\mathrm{ET}+\mathrm{CT} / \mathrm{TT} / \mathrm{IT}$ & 1315 & 1.22 & {$[1.11 ; 1.34]$} & \\
\hline \multirow[t]{3}{*}{ Center Size } & $<500$ & 312 & 1 & & \multirow[t]{3}{*}{0.2} \\
\hline & $500-800$ & 3834 & 1.11 & {$[0.95 ; 1.3]$} & \\
\hline & $>800$ & 1406 & 1.05 & {$[0.89 ; 1.24]$} & \\
\hline
\end{tabular}

HR : Hazard Ratio. L1: First line of systemic therapy. TN: Triple Negative (HR- HER2-). ET: Endocrine Therapy. CT/TT/IT: chemotherapy/Targeted Therapy/Immunotherapy. "Center size" represent the number 
Figures

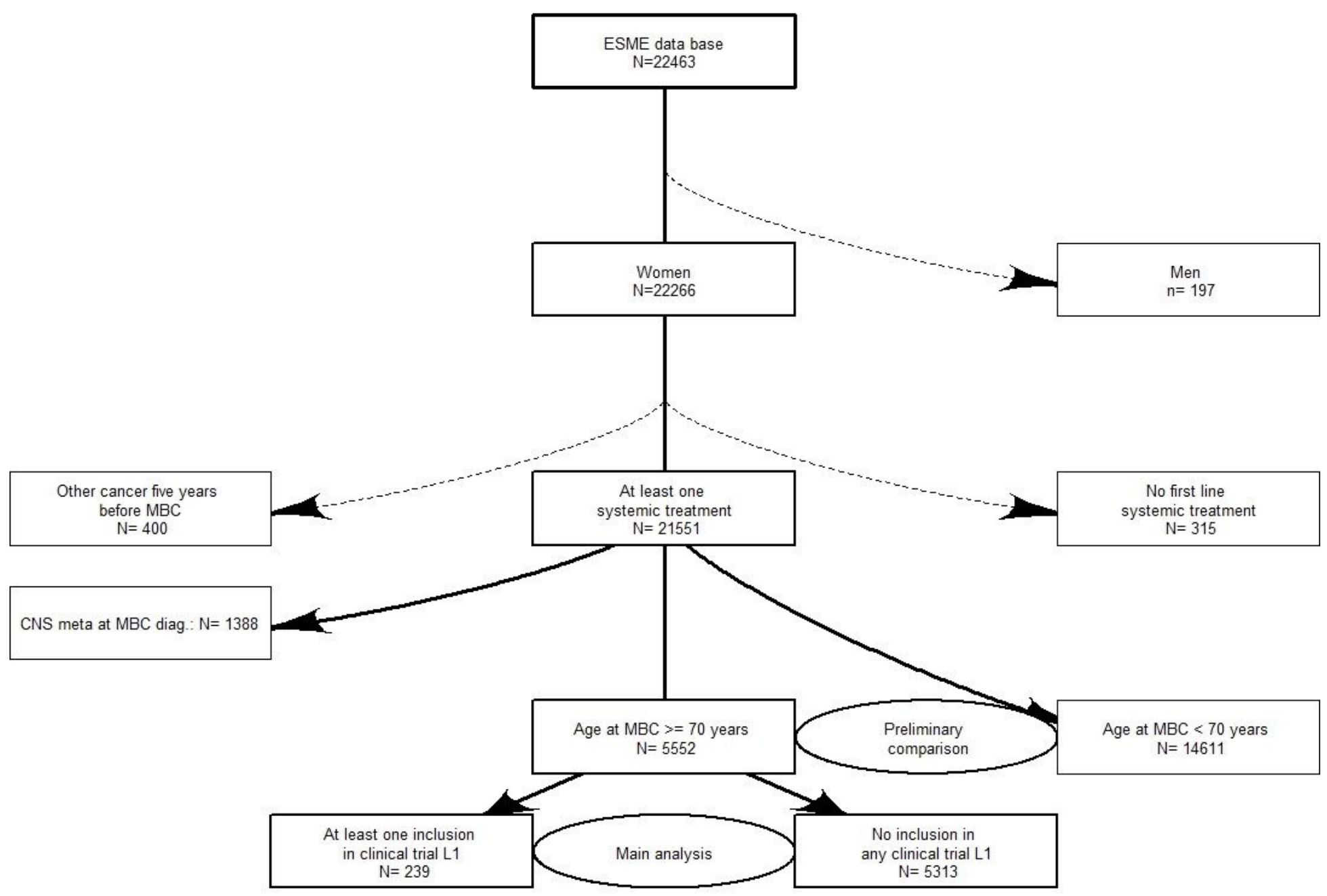

Figure 1

flow-chart 


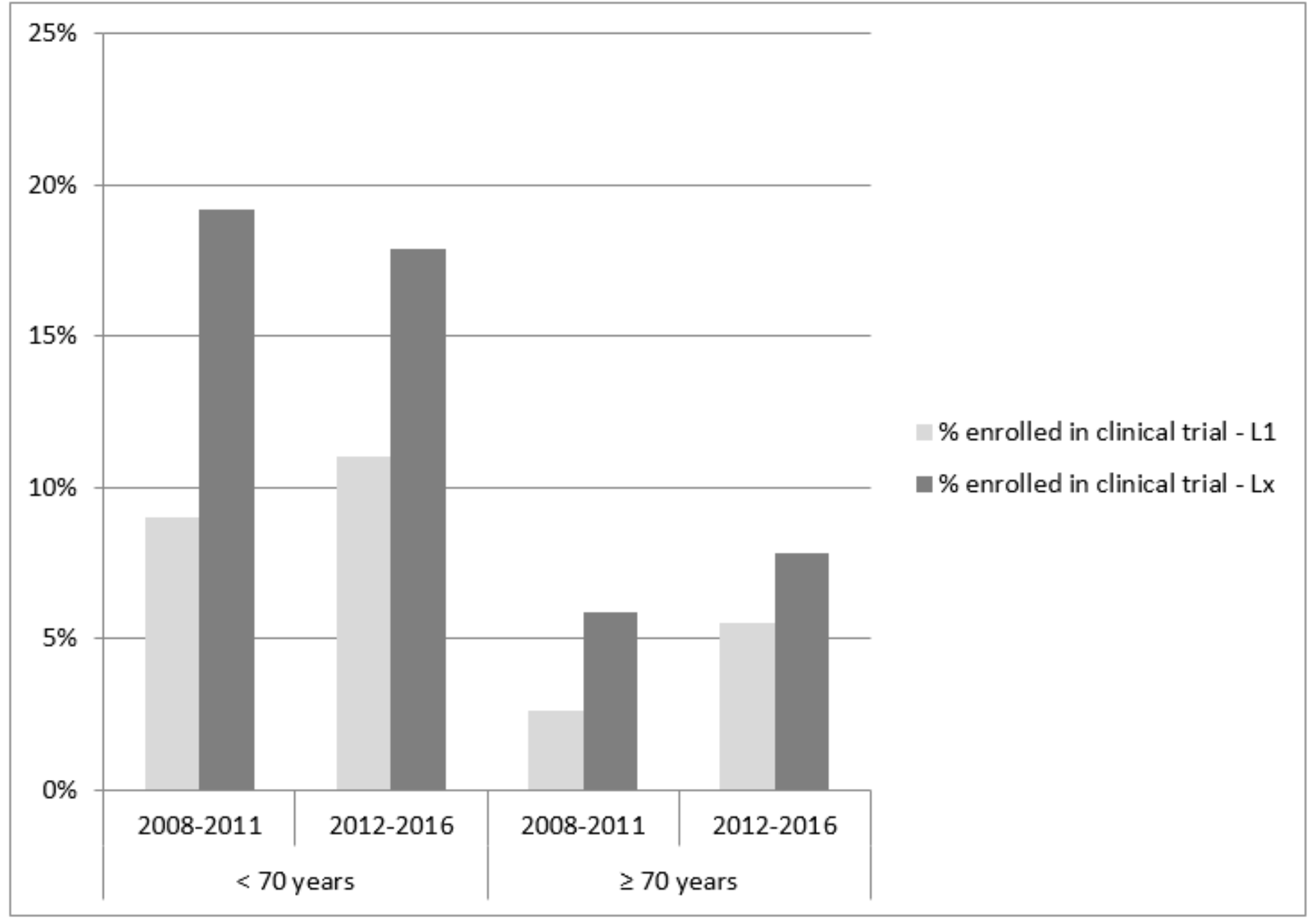

\section{Figure 2}

Evolution of enrollment in clinical trials in younger and older patients (threshold 70yo) over time (periods 2008-2011 and 2012-2016) in first line of treatment (L1) and in all-lines of treatment (Lx) in metastatic breast cancer. 


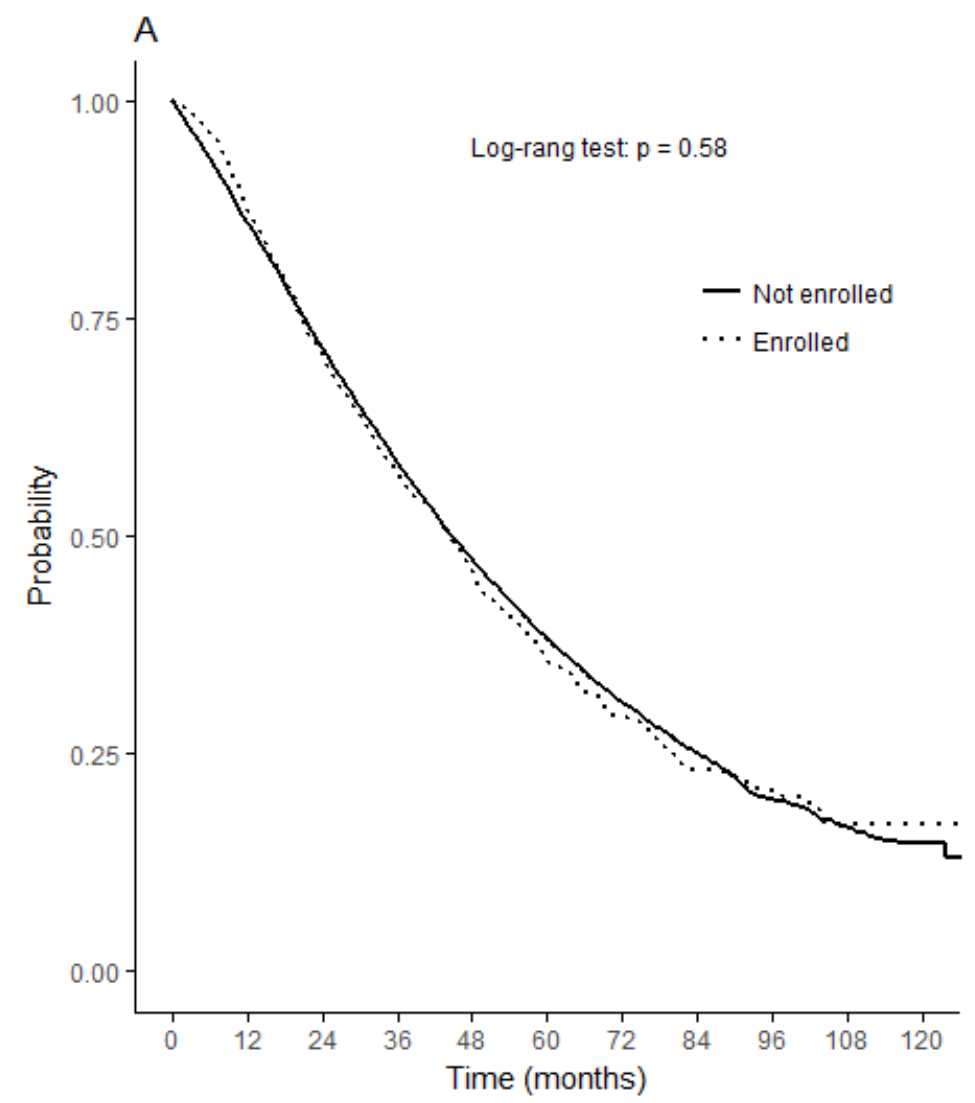

Number at risk

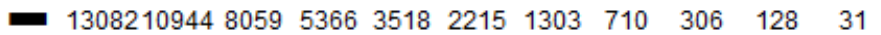

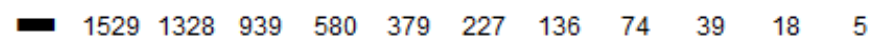

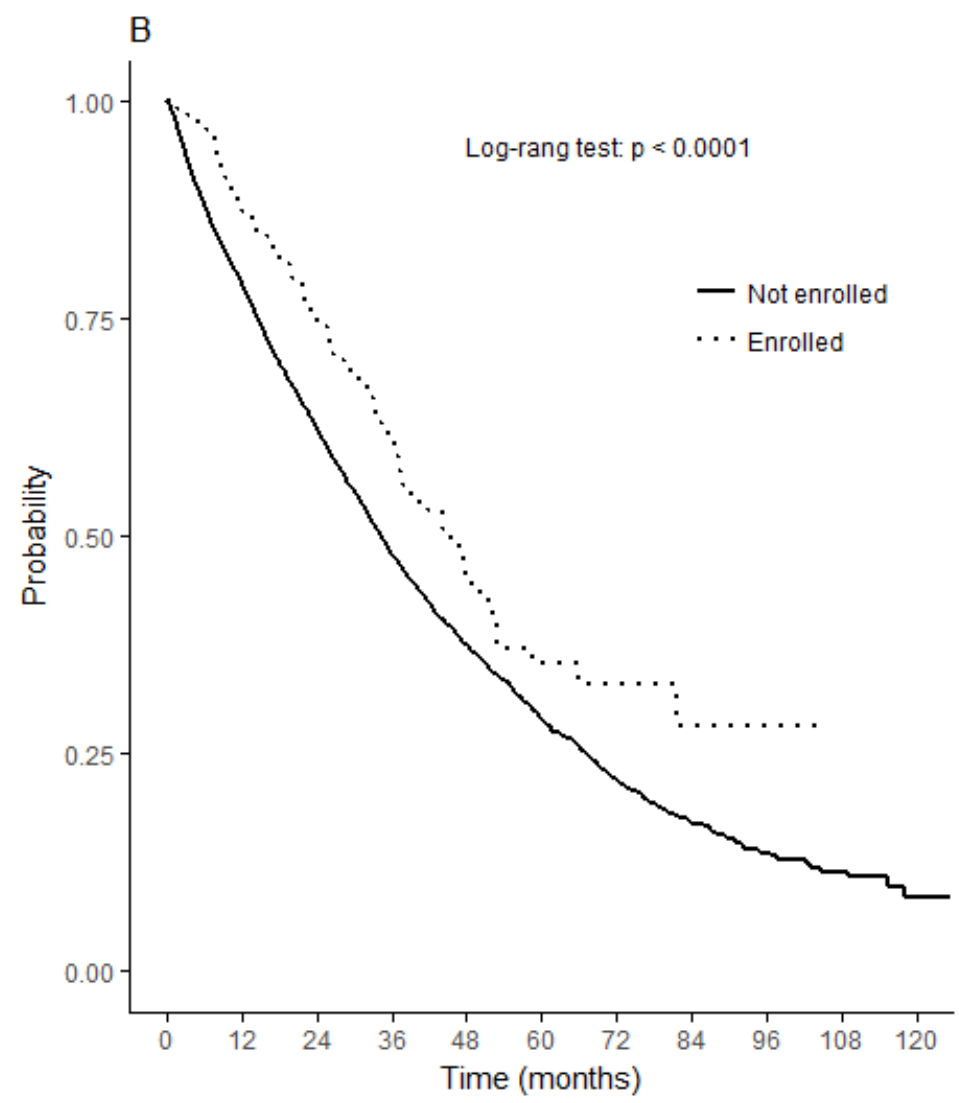

Number at risk

— $\begin{array}{lllllllllll}5313 & 3925 & 2667 & 1609 & 990 & 545 & 278 & 144 & 55 & 18 & 4\end{array}$

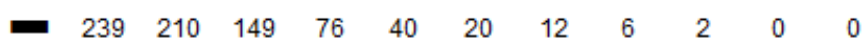

\section{Figure 3}

Overall Survival considering enrollment in a first line trial in Metastatic Breast Cancer in younger patients (Fig3A) and in older patients (Fig3B), with a threshold of 70yo. 


\section{Survie relative - Ederer2}

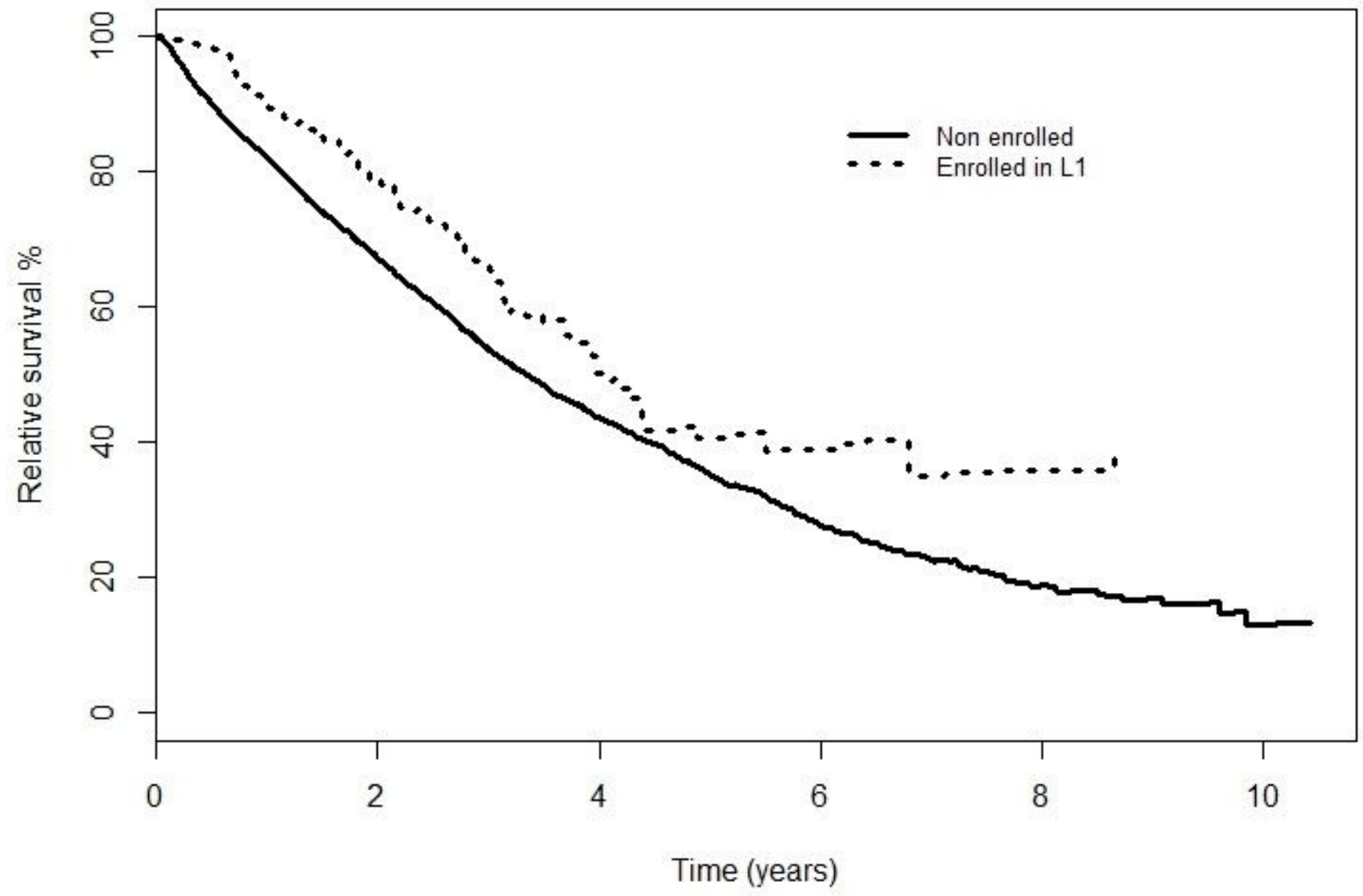

Figure 4

Relative Survival considering enrollment in a first line trial in Metastatic Breast Cancer in older patients

\section{Supplementary Files}

This is a list of supplementary files associated with this preprint. Click to download.

- SupplementaryTables.docx 